\title{
Dysphagia as the first manifestation of tuberculosis
}

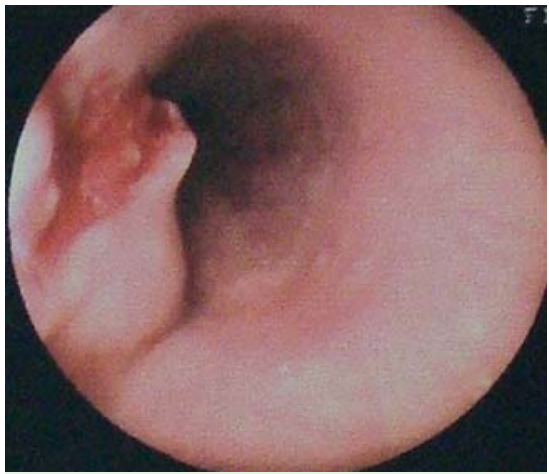

Fig. 1 Eccentric ulcerated lesion in the mid esophagus.

A 38-year-old man presented with progressively increasing mechanical dysphagia associated with anorexia and weight loss. Clinical examination did not reveal any significant findings. The hematological and biochemical investigations were normal. The upper gastrointestinal endoscopy performed at the referring hospital revealed an eccentric ulcerated lesion in the mid esophagus ( $\bullet$ Fig. 1 ), and the histological examination of endoscopic biopsies was inconclusive.

Computed tomography (CT) of the chest revealed a thickened esophageal wall ( Fig. 2) with enlarged mediastinal lymph nodes. The patient was referred to us for endoscopic ultrasound (EUS).

EUS revealed multiple enlarged mediastinal lymph nodes; one of the large subcarinal lymph nodes was noted to infiltrate across the esophageal wall into the lumen ( Fig. $\mathbf{3} \mathbf{a}$ and $\mathbf{3 b}$ ).

This lesion corresponded to the ulcerated lesion noted on endoscopy. EUS-guided fine needle aspiration cytology (FNAC) from the lesion revealed epithelioid cell granulomas with numerous polymorphs and lymphocytes, and the stain for acid-

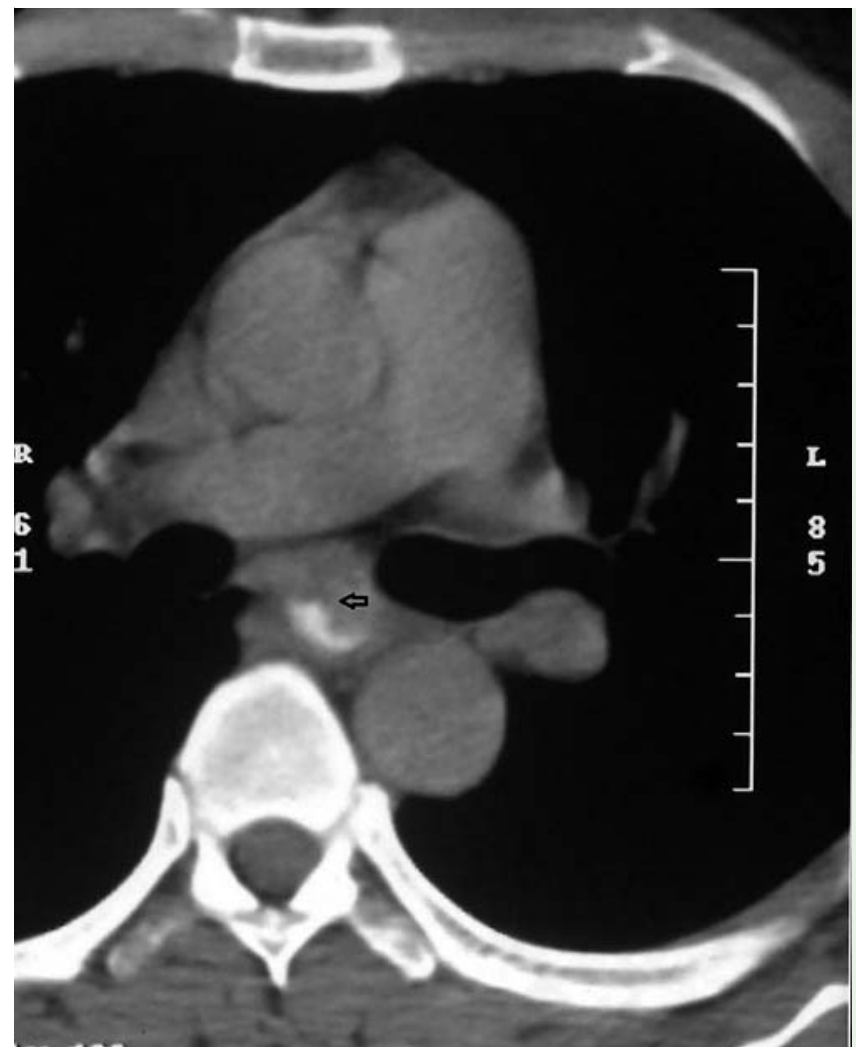

Fig. 2 Computed tomography (CT) showing thickened esophageal wall (arrow).

fast bacilli was positive. The patient was initiated on a four-drug antitubercular therapy with marked improvement in his symptoms.

Esophageal tuberculosis is rare and is often secondary to spread from adjacent sites such as mediastinal or hilar lymph nodes, pulmonary infection, infected vertebral bodies, or from extension from the larynx or pharynx [1]. The usual presentation is due to dysphagia, retrosternal pain, fever, cough and expectoration, and weight loss [1,2]. Complications may include hemorrhage from the lesion, development of arterioesophageal fistula, esophagocutaneous fistula, or tracheo- esophageal fistula $[1,2]$. As in the present case, the middle esophagus is the most common site of involvement. Endoscopic findings may include ulcer, growth, infiltrative growth, stricture, fistula, or extrinsic compression [1,2]. Tubercular necrotic mediastinal lymph nodes may erode into the esophagus, leading to hematemesis or fistula formation $[3,4]$. However, mediastinal lymph nodes eroding into the esophagus and presenting as a polypoidal mass is very rare.

Endoscopy_UCTN_Code_CCL_1AB_2AC_3AZ

Competing interests: None 


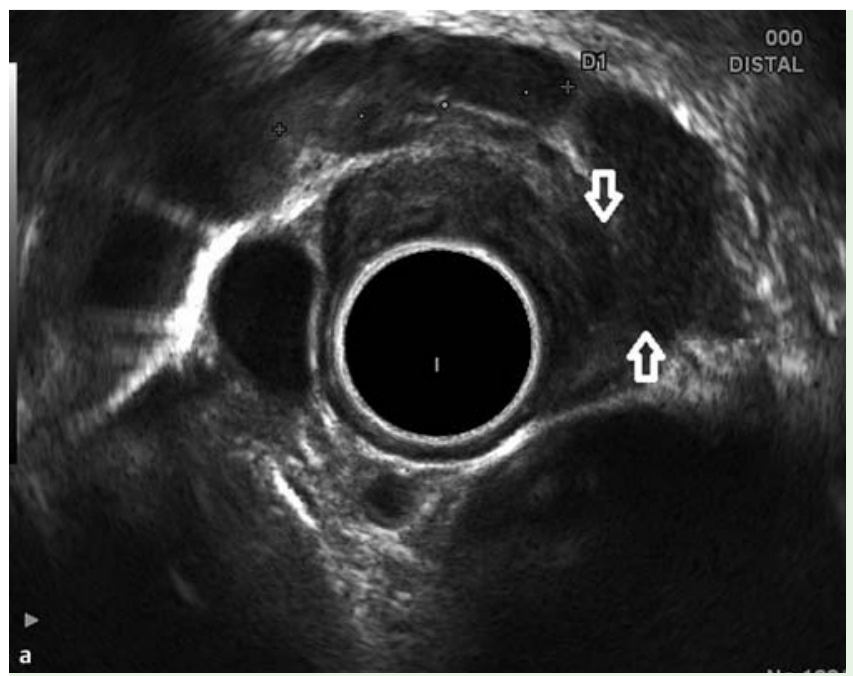

Fig. 3 a, b Endoscopic ultrasound (EUS) showing a subcarinal lymph node eroding into the esophagus wall (arrows).

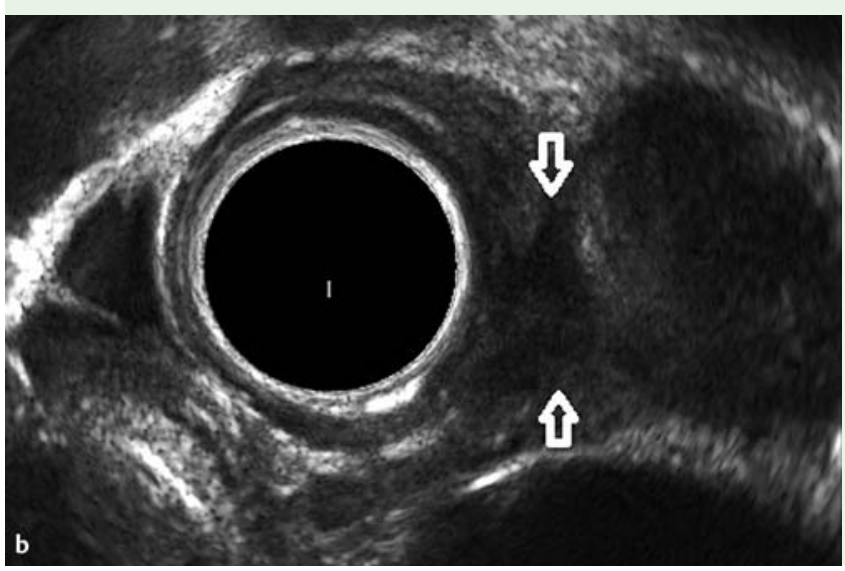

S. S. Rana, D. K. Bhasin,

\section{Sharma, V. Chaudhary, K. Singh}

Department of Gastroenterology, Postgraduate Institute of Medical Education and Research (PGIMER), Chandigarh, India

\section{References}

1 Mokoena T, Shama DM, Ngakane H, Bryer JV. Oesophageal tuberculosis: a review of eleven cases. Postgrad Med J 1992; 68: $110-115$

2 Jain SK, Jain S, Jain M, Yaduvanshi A. Esophageal tuberculosis: is it so rare? Report of 12 cases and review of the literature. Am J Gastroenterol 2002; 97: 287-291

3 Newman RM, Fleshner PR, Lajam FE, Kim U. Esophageal tuberculosis: a rare presentation with hematemesis. Am J Gastroenterol 1991; 86: 751 - 755

4 Macchiarini P, Delamare N, Beuzeboc P et al. Tracheoesophageal fistula caused by mycobacterial tuberculosis adenopathy. Ann Thorac Surg 1993; 55: 1561 - 1563

\section{Bibliography}

DOI $10.1055 / \mathrm{s}-0030-1256456$

Endoscopy 2011; 43: E300 - E301

(c) Georg Thieme Verlag KG Stuttgart · New York . ISSN 0013-726X

\section{Corresponding author}

\section{S. S. Rana, MD}

Department of Gastroenterology

Postgraduate Institute of Medical Education and Research (PGIMER)

Chandigarh 160012

India

Fax: +91-172-2744401

drsurinderrana@yahoo.co.in 